\title{
Reliability Worth Assessment in Composite Power System Planning and Operation
}

\author{
Ali Khraiwish Dalabeeh ${ }^{1} \&$ Eng.Hani Hasan Saleh Al-Hajbi ${ }^{2}$ \\ ${ }^{1}$ Department of Electrical Engineering, Faculty of Engineering Technology, Al-Balqa' Applied University, \\ Jordan \\ ${ }^{2}$ National Electric Power Company, Amman, Jordan \\ Correspondence: Ali Khraiwish Dalabeeh, Department of Electrical Engineering, Faculty of Engineering \\ Technology, Al-Balqa' Applied University, P.O.BOX 15008, Amman 11134, Jordan. E-mail: \\ alidalabeeh@yahoo.com
}

Received: May 20, 2014

doi:10.5539/mas.v8n5p45
Accepted: June 3, $2014 \quad$ Online Published: August 6, 2014

URL: http://dx.doi.org/10.5539/mas.v8n5p45

\begin{abstract}
This study presents a comprehensive procedure for evaluating the reliability indices incorporating reduction in interruption cost, and to relate reliability investments with customer's benefits. An analytical algorithm is used to obtain the final optimal operational solution by determining unit commitment for each generating unit to reach the maximum profit (minimizing cost) subjected to operational constraints. The paper describes a method based on the complementing short-term planning with long-term planning take into account the cost benefit approach. The proposed method has been demonstrated on the RBTS to show the feasibility and the economic effect of the proposed method, and was applied to the Jordanian Electric Power System (JEPS) to show its application capability.
\end{abstract}

Keywords: reliability indices, power system planning, power system operation, interruption cost

\section{Introduction}

The primary function of a modern power system is to supply its customers with electrical energy as economically as possible with an acceptable degree of reliability. Load curtailment takes place in the system as a result of the inadequacy of the generation unit's capacity to meet the demand or the deficiencies in transmission lines. This is a result of poor planning and failure to take the appropriate steps to use available resources to meet deal with the increase in future loads economically with acceptable reliability and quality. Evaluation of restructured power systems provide both economic and reliability information for generation companies and transmission companies to enhance generation capacity and to expand transmission lines, so a decision should be made to choose among the various transmission system expansion or the new generating units addition alternatives the most reliable and beneficial one not only from a power utility' standpoint but also from customers' viewpoint. There is a need to know customer and user outage costs and to be included and considered in system planning and operational decisions. Power suppliers aimed to enhance system reliability within the available amount of investment while the customer needs fewer service interruptions, and less destruction caused by these interruptions. The main objective of power system restructuring and deregulation is to introduce competition in the power industry and to allow customers to select their suppliers based on price and reliability (Wang \& Billinton, 2003). In recent years and at the same time as the restructuring in the power industry, various studies have been carried out into the Transmission Expansion Planning (TEP) in electricity markets and its adjustment to market conditions (Shayeghi, et al., 2008; Buygi, et al., 2003; Wu, et al., 2006). In Sirjani, et al., (2008) and $\mathrm{Fu}$, et al. (2008), there are some criteria and models for creating competition in the electricity market. In (De la Torre, et al., 2008), by considering that users' benefit increase is one of the TEP goals a model is presented that can be utilized by all participants. Also, in Shrestha and Fonseka (2004), optimization the users' benefit and investment cost is evaluated as a single-objective model. In Wangdee (2005), Eliassi, et al., (2009), a probabilistic criterion, known as Expected Customer Interruption Cost (ECOST) due to transmission constraint is presented to evaluate the value of reliability. In (Bresesti, et al, 2009), a method is presented for evaluating the users' benefit and reliability in TEP, which is based on Monte Carlo simulation. TEP should serve its users, so the benefit of both participants in the market and investment cost are considered as economic criteria for the 
electricity market, and the congestion cost of the network as a factor for encouraging market competition, also a probabilistic criterion was considered to evaluate the value of reliability (Mohammad \& Mojtaba, 2011). TEP model need to include the most relevant short-term transmission related details of electricity markets into the network expansion planning (Fonseka \& Shrestha, 2009), Markets in different deregulated power systems are operated by different organizations. These markets operate on either day-ahead or hour-ahead market policy. The most common form of market at present is Power Pool. In a pool system both generating utilities and customers bid for selling and buying electrical power. A generating utility would be out of the competitive market if its price is too high and on the other hand a customer would have no power if its offer were too low. Thus the pool fixes a single price for every hour which is determined by basic supply demand relationship of economics (Shahidephour, et al., 2002; Weron, 2006). The price of electricity is the most important signal to all market participants and the most basic pricing concept is market-clearing price. The intersection of demand and the stepped bid curve determines the market clearing price. The market operators are responsible to maintain a balance between the supply and demand of power. All successful bidders will get paid the market clearing price irrespective of their bidding prices. The fear of getting out of business encourages the supplier to bid the most competitive prices in order to compete for dispatch in the wholesale marketplace (Shahidephour, et al., 2002; Weron, 2006). In a deregulated power system generating utilities and customers may sign contracts for selling and buying of power in addition to the existence of a power pool.

\section{Proposed Method}

The proposed method is addressed in this section and an illustrative RBTS is employed to clarify the issue. For the sake of effectiveness and simplicity the method is based on the two state models of the generating units and transmission lines, a Markov state of the studied system is defined where every component is in a given operating state. The up state represents the unit available with full capacity; the down state represents the unit out of service. All the possible states of the studied system make up the state space. A generating and transmission failure state array as a sampling tool is constructed using a Generic Algorithm (GA) (Samaan, 2004). Demand is modelled as annualized or annual load. The amount of curtailed load, if needed, is determined for the whole system at each load bus for each sampled state by using a load flow program.) As the sampling process stops, the annualized (or annual) indices are calculated for the whole system and at each load bus. The probability of any two state generation unit to be down is equal to its forced outage rate and the probability failure of a two state transmission line (PTi) is calculated using its failure rate $\left(\lambda_{\mathrm{i}}\right)$ and repair rate $\left(\mu_{\mathrm{i}}\right)$ as follows (Samaan, 2004).

$$
P T_{i}=\frac{\lambda_{i}}{\left(\lambda_{i}+\mu_{i}\right)}
$$

The total number of states $\left(\mathrm{N}_{\text {states }}\right)$ for all possible combinations of generating units and transmission lines installed is:

$$
\mathrm{N}_{\text {states }}=2^{\text {ng+nt }}
$$

Where (ng) is the total number of generation units and (nt) is the total number of transmission lines in the system.Each possible combination is considered as a raw which represents a system state. A search for failure system state is done and save such states in a state array. Each raw consists of a binary number genes. Each number represents the component's state in the state sample (contingency). The first (ng) in the raw represent generation units while the remaining (nt) represent transmission lines. If any component takes a zero value this means that the component is in the down state while a one value means the component is in the up state. To illustrate the raw construction, consider the small RBTS test system shown in Figure 2. It consists of 2 generator (PV) buses, 4 load (PQ) buses, 9 transmission lines and 11 generating units.

Consider the state that all system components are up, the raw (system state) representing this state is:

$$
\left[\begin{array}{llllllllllllllllllll}
1 & 1 & 1 & 1 & 1 & 1 & 1 & 1 & 1 & 1 & 1 & 1 & 1 & 1 & 1 & 1 & 1 & 1 & 1 & 1
\end{array}\right]
$$

Where the first four elements represent the four generation units (40MW, 40MW, 20MW and 10MW, respectively) at busbar number one, the second seven elements represent the seven generation units (40MW, 20MW, 20MW, 20MW, 20MW, 5MW and 5MW respectively) at busbar number two, the remaining nine elements represent the nine transmission lines in the system. The state probability calculated for each system state, the system states with an associated state probability greater than a threshold value is considered while the remaining system states removed from the evaluation process to reduce the processing time with a negligible error. Each considered system state is evaluated through an evaluation function. The evaluation function returns zero if it is a success state and a state probability if it is a failure state. The failure states that include outages up to a given order only considered also to reduce the processing time. For the failure considered states, the 
evaluation function calls a linear programming optimization load flow model that to determine the amount of load curtailment for the load buses in the system. If no load curtailment is needed, then the failure considered state is a success state, otherwise it represents a failure state. The annualized (or annual) reliability indices for each load bus and for the whole system is calculated [Appendix A \& B]. Then the annual expected interruption costs are evaluated. These outage costs can then be used as input data to worth assessments of system planning and operational decisions. To enhance the system reliability by adding new transmission lines or new generating units various alternatives should be considered. To select the beneficial alternative the annual expected interruption costs (EIC) re-evaluated and the one which has the much lower EIC has to be chosen. The price of electricity is important signal to all market participants and the most basic pricing concept is market-clearing price which is as states previously is the intersection of demand and the stepped bid curve. The market operators are responsible to maintain a balance between the supply and demand of power. All successful bidders will get paid the market clearing price irrespective of their bidding prices. In the environment of the power market to maintain a balance between the supply and demand of power based on the cost benefit approach, an optimisation models should be established to find the optimal units operations. The expected duration, within a certain period of time over which the load demand exceeds the total generated power, is calculated based on the units that are cleared in the market (the units cleared in market depend on the demand and the reserve) and the expected energy not supplied for every hour also calculated to find the optimal units operations (reach the maximum profit) to supply market demand for each hour. The proposed method illustrated in flow chart as shown in Figure 1.

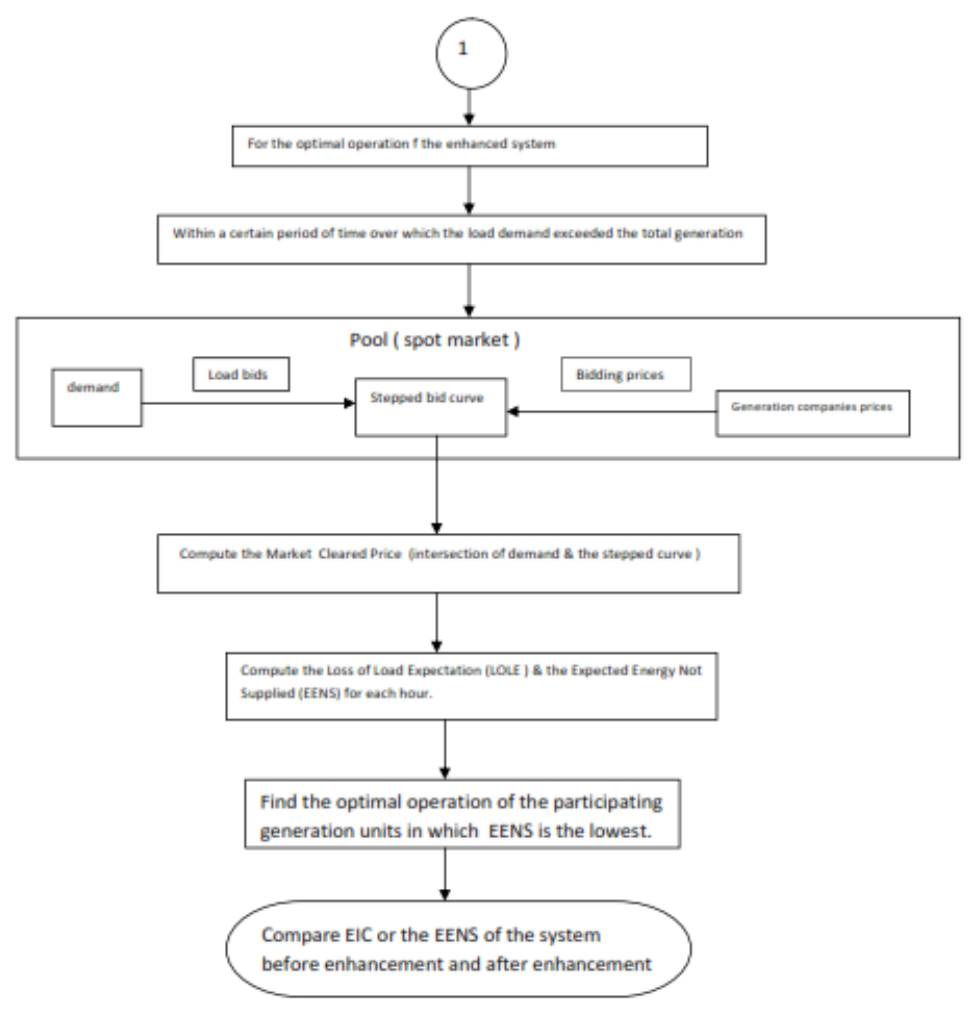

Figure 1. Flow-Chart of the System Short-Term Operation Stage

\section{Case Study}

\subsection{Reliability worth Assessment in Composite System Planning of RBTS}

RBTS (Figure 2) is used to evaluate the annual expected interruption costs of three alternatives:

(A1): the addition of transmission line between Buses 3 and $5(50 \mathrm{Km})$.

(A2): the addition of a transmission line between Buses 5 and $6(50 \mathrm{Km})$.

(A3): the addition of a generating unit at Bus $6(20 \mathrm{Km})$. 


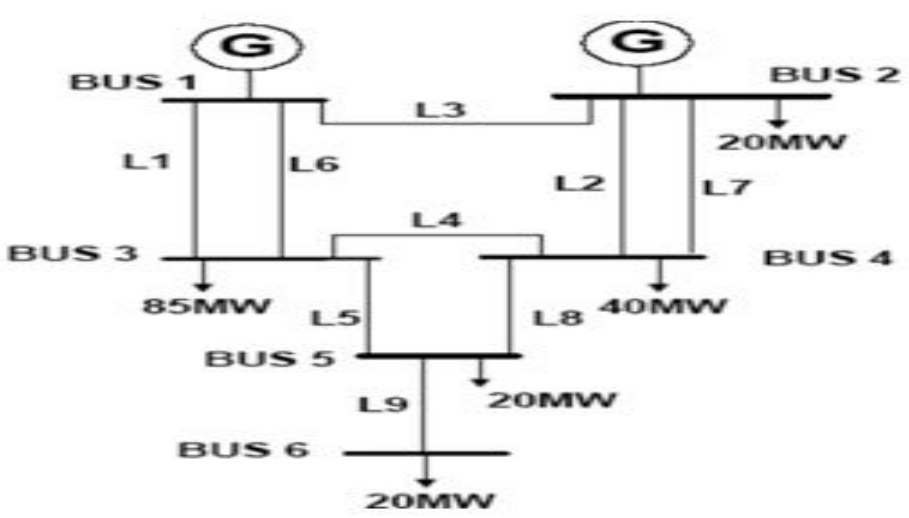

Figure 2. 6-bus RBTS

Table 1, Shows the annual expected energy not supplied (EENS), expected interruption costs (EIC), and interruption energy assessment rate (IEAR) in the RBTS at different Load Levels $(0.0 \%-10.0 \%) \mathrm{MW}$. The annual expected interruption costs (EIC) of the base system and the three alternatives for load increment $0 \%, 2 \%$, $4 \%, 6 \%, 8 \%$, and $10 \%$ are shown in Table 2 . It can be seen that alternative 1 (A1) has basically the same EIC indices as the base case. This means that the addition of the line between Buses 3 and 5 does not improve the reliability of the system. A2 is the addition of the shorter line between Buses 5 and 6 which leads to much lower EIC than A1. This indicates that the different line addition location have completely different impacts on composite system reliability. It is interesting to note that A2 have higher EIC values than A3 for load increases from to $0 \%$ to $10 \%$. A $20 \mathrm{MW}$ generating unit requires much higher investment cost than one $50 \mathrm{Km}$ line.

Table 1. Annual EENS, EIC, and IEAR in the RBTS at different load levels

\begin{tabular}{ccccc}
\hline $\begin{array}{c}\text { Load } \\
\text { increment } \%\end{array}$ & Peak Load MW & EENS MWh/yr & EIC $(\mathrm{k} \$ / \mathrm{yr})$ & IEAR $(\$ / \mathrm{kWh})$ \\
\hline 0.0 & 185 & 147.84 & 629.32 & 4.21 \\
2.0 & 188.7 & 166.48 & 703.34 & 4.22 \\
4.0 & 192.4 & 180.28 & 764.26 & 4.24 \\
6.0 & 196.1 & 193.00 & 823.67 & 4.27 \\
8.0 & 199.8 & 212.34 & 907.12 & 4.27 \\
10.0 & 203.5 & 237.40 & 1022.57 & 4.31 \\
\hline
\end{tabular}

Table 2. EIC Indices of the base system and Three alternatives for RBTS(k\$/yr)

\begin{tabular}{ccccc}
\hline Load & Base System & \multicolumn{3}{c}{ Alternatives } \\
\cline { 3 - 5 } Increment $\%$ & & $\mathrm{~A} 1$ & $\mathrm{~A} 2$ & $\mathrm{~A} 3$ \\
\hline 0.0 & 629.32 & 622.73 & 88.41 & 28.12 \\
2.0 & 703.34 & 697.75 & 110.18 & 31.89 \\
4.0 & 764.26 & 754.38 & 168.93 & 39.12 \\
6.0 & 823.67 & 816.91 & 221.47 & 55.31 \\
8.0 & 907.12 & 901.96 & 297.46 & 74.57 \\
10.0 & 1022.57 & 1014.21 & 384.74 & 101.44 \\
\hline
\end{tabular}

Table 3. The annual investment for all alternatives in RBTS

\begin{tabular}{lll}
\hline No. & Alternatives description & Annual investment \\
\hline A1 & Add line $(50 \mathrm{Km}) @$ Bus 3-5 & Rejected \\
A2 & Add line $(50 \mathrm{Km}) @$ Bus 5-6 & $281.11 \mathrm{k} \$ / \mathrm{yr}$ \\
A3 & Add generator unit $(20 \mathrm{MW}) @$ Bus 6 & $1803.35 \mathrm{k} \$ / \mathrm{yr}$ \\
\hline
\end{tabular}


Further analysis can be conducted to evaluate the total cost, which is the sum of annual expected interruption cost and annual investment for the alternatives. The economic life of the power system facilities was assumed to be 30 years and the discount rate $10 \%$. The unit capital cost of a $230 \mathrm{KV}$ line is $53 \$ / \mathrm{Km}$ and the capital cost of a 20MW generating unit 17M\$. The annual investment for all alternatives can be shown in Table 3 . At the present load level $(0.0 \%)$, Alternative 2 can reduce the expected interruption cost by $540.91 \mathrm{k} \$ / \mathrm{yr}(629.32-88.41)$. This reduction in much larger than its annual investment of $281.11 \mathrm{k} \$ / \mathrm{yr}$ and therefore Alternative 2 is a beneficial option even the present load level. On the other hand, the reduction of the EIC due to Alternative 3 at $10.0 \%$ load increment is $921.13 \mathrm{k} \$ / \mathrm{yr}(1022.57-101.44)$. This reduction is still smaller than the annual investment of A3 $(1803.35 \mathrm{k} \% / \mathrm{yr})$. This indicates that the addition of the $20 \mathrm{MW}$ generating unit is not a cost effective option even when the load has $10.0 \%$ growth.

\subsection{Reliability worth Assessment in Composite System Operation of RBTS}

Table 4. Generating Unit data for the RBTS

\begin{tabular}{lllll}
\hline Economical Loading order & Company & Unit Size & Unit No. & Forced Outage Rate \\
\hline 1 & Genco 1 & 40 & 7 & 0.020 \\
2 & Genco 1 & 20 & 3 & 0.015 \\
3 & Genco 1 & 20 & 4 & 0.015 \\
4 & Genco 2 & 40 & 10 & 0.030 \\
5 & Genco 2 & 40 & 11 & 0.030 \\
6 & Genco 2 & 20 & 9 & 0.025 \\
7 & Genco 2 & 10 & 8 & 0.025 \\
8 & Genco 1 & 20 & 5 & 0.015 \\
9 & Genco 1 & 20 & 6 & 0.015 \\
10 & Genco 1 & 5 & 1 & 0.010 \\
11 & Genco 1 & 5 & 2 & 0.010 \\
\hline
\end{tabular}

Also RBTS is used to study the reliability indices in a spot market. It is assumed that two generating companies own the generators at bus 1 and bus 2 . Genco 1 owns the seven hydro units at bus 2 with a total capacity of 130 MW. The four thermal units with a total capacity of $110 \mathrm{MW}$ at bus 1 are considered as Genco 2. The total installed capacity of the test system is $240 \mathrm{MW}$. The two generating companies bid into the pool to meet the demand at buses $2,3,4,5$, and 6 . It is assumed that the generating companies bid according to the economical loading order of the generators. The economical loading order of the generators, their forced outage rates and rating of the generating units are shown in Table 4.

Table 5. Reliability indices for two typical hours in the spot market

\begin{tabular}{llllllll}
\hline $\begin{array}{l}\text { Typical } \\
\text { Hour }\end{array}$ & Demand & $\begin{array}{l}\text { Demand } \\
\text { Reserve }\end{array}$ & $\begin{array}{l}\text { Units } \\
\text { committed } \\
(\text { Genco } 1)\end{array}$ & $\begin{array}{l}\text { Units } \\
\text { committed } \\
(\text { Genco 2) }\end{array}$ & $\begin{array}{l}\text { Committed } \\
\text { Capacity(MW) }\end{array}$ & $\begin{array}{l}\text { LOLE } \\
(\mathrm{h} / \mathrm{h})\end{array}$ & $\begin{array}{l}\text { EENS } \\
(\mathrm{MWh} / \mathrm{h})\end{array}$ \\
\hline 4354 & 105.13 & 115.643 & $7,3,4$ & 10 & 120.0 & 0.082 & 1.94 \\
2622 & 83.472 & 91.819 & $7,3,4$ & 10 & 120.0 & 0.052 & 0.46 \\
\hline
\end{tabular}

Table 6. The effect on reliability indices due to Gencos' choice in participating

\begin{tabular}{llllllll}
\hline Case & $\begin{array}{l}\text { Units } \\
\text { participating }\end{array}$ & Demand & $\begin{array}{l}\text { Committed } \\
\text { Capacity }\end{array}$ & $\begin{array}{l}\text { Committed } \\
\text { Units of } \\
\text { Genco } 1\end{array}$ & $\begin{array}{l}\text { Committed } \\
\text { Units of } \\
\text { Genco 2 }\end{array}$ & $\begin{array}{l}\text { LOLE } \\
(\mathrm{h} / \mathrm{h})\end{array}$ & $\begin{array}{l}\text { EENS } \\
(\mathrm{MWh} / \mathrm{h})\end{array}$ \\
\hline 1 & $4,10,11,9,8,6,5$ & 105.13 & 120.0 & 4 & $10,11,9$ & 0.0951 & 1.4952 \\
2 & $7,3,10,9,8,5,6$ & 105.13 & 120.0 & 7,3 & 19,9 & 0.0896 & 1.3608 \\
3 & $4,10,9,5,6,1,2$ & 105.13 & 120.0 & $4,5,6$ & 10,9 & 0.0999 & 0.9936 \\
\hline
\end{tabular}


Table 7. The effect on reliability indices due to capacity and participate Gencos

\begin{tabular}{|c|c|c|c|c|c|c|}
\hline Units participating & Demand & Committed & Committed & Committed & LOLE & EENS \\
\hline & & Capacity & $\begin{array}{l}\text { units } \\
\text { Genco } 1\end{array}$ & $\begin{array}{l}\text { Units } \\
\text { Genco } 2\end{array}$ & $(\mathrm{~h} / \mathrm{h})$ & $(\mathrm{MWh} / \mathrm{h})$ \\
\hline $7,3,4,10,11,9,8,5,6,1,2$ & 105.13 & 120.0 & $7,3,4$ & 10 & 0.082 & 1.94 \\
\hline $7,4,10,11,9,8,5,6$ & 105.13 & 140.0 & 7,4 & 10,11 & 0.078 & 0.91 \\
\hline
\end{tabular}

The annual curve of the test system has 8760 points that is dependent on the annual system peak load, weakly peak load in percentage of annual peak, daily peak load in percent of weekly peak, and hourly peak load in percentage of the daily peak load, the annual system peak load is taken as $185 \mathrm{MW}$. The reliability of the system can be expressed by many reliability indices. Two reliability indices namely loss of load expectation (LOLE) and expected energy not supplied (EENS), which can provide consistent measures of the reliability of the system are determined in this paper. The reliability indices are determined based on the units cleared in the market. The units cleared in the market depend on the demand and the reserve. The operating reserve is taken as ten percent of the demand predicted. Reliability indices are calculated for every hour in the spot market based on the demand for that hour. Reliability indices for the 4354th hour and the 2622nd hour of the year are shown in Table.5. It is assumed that all the generators bid at their marginal costs for these hours. The total demand is different in both the cases but the committed capacity is the same. Reserve margin is $14.1 \%$ of the load for the 4354the hour. $43.8 \%$ reserve is provided for the 2622nd hour. The reliability indices in the first case are higher compared to those of the latter. Table 6 shows the effect on the reliability indices due to the choice of the generating companies to participate, on a typical hour (4354th hour) of the spot market for the same demand and committed capacity. For the first two cases shown in the table, generators 10 and 9 are committed. In the case generator 4 (of Genco 1) is participating to meet the load as against generator 3 (of Genco 1) in the second case. This difference in choosing generating units may not affect the reliability indices as both these generating units have the same rating, failure and repair rates. Generator 11 (of Genco 2) in the first case has a FOR of 0,03 but generator 7(of Genco 1) in the second case has a FOR of 0.02 , although both have the same capacity. Since the less reliable generator is participating in the first case, the LOLE and EENS in this case are much more than the corresponding values in the second case. The change in the reliability indices in the first and the third case is due to the number of generators participating in the market for the same committed capacity and demand. In both cases generators 4, 10 , and 9 are participating. In the first case generator 11 of $40 \mathrm{MW}$ is participating whereas in the third case two generators 4 and 6 of capacity $20 \mathrm{MW}$ each are participating to meet the load. For this demand and the choice of units, the participation of the bigger unit is showing better reliability than two smaller units of same capacity. Another example in Table 7 shows the reliability indices for two cases of different choice of Gencos to participate in the market and different capacities.

\section{An Application Case of the Proposed Method}

\subsection{Application of Reliability worth Assessment in JEPS Planning}

JEPS (single line diagram is shown in Appendix A.3) is used to evaluate the annual expected interruption costs of four alternatives:

(A1): the addition of a $132 \mathrm{KV}$ double circuit OHL between Buses 17 and 19 (70 Km).

(A2): the addition of a $400 \mathrm{KV}$ double circuit OHL between Buses 1 and $4(360 \mathrm{Km})$.

(A3); the addition of a generating unit at Bus 20 (20 MW).

(A4): the addition of a generating unit at Bus 4 (120 MW).

Table 8. System EENS, EIC, and IEAR in the JEPS at different load levels

\begin{tabular}{lllll}
\hline Load increment \% & Peak Load (MW) & EENS $(\mathrm{MWh} / \mathrm{yr})$ & EIC $(\mathrm{K} \$ / \mathrm{yr})$ & IEAR $(\$ / \mathrm{kWh})$ \\
\hline 0.0 & 2230.00 & 2219.55 & 22982.39 & 10.35 \\
2.0 & 2274.60 & 3845.30 & 41225.69 & 10.36 \\
4.0 & 2319.20 & 7760.53 & 80572.70 & 10.38 \\
6.0 & 2363.80 & 14900.42 & 154918.22 & 10.40 \\
8.0 & 2408.40 & 27977.45 & 292524.49 & 10.46 \\
10.0 & 2453.00 & 48744.72 & 506006.02 & 10.38 \\
\hline
\end{tabular}


Table 9. EIC Indices of the Base System and Four Alternatives for JEPS (K\$/yr)

\begin{tabular}{|c|c|c|c|c|c|}
\hline \multirow{2}{*}{$\begin{array}{l}\text { Load } \\
\text { Increment \% }\end{array}$} & \multirow[t]{2}{*}{ Base System } & \multicolumn{4}{|l|}{ Alternatives } \\
\hline & & A1 & A2 & A3 & A4 \\
\hline 0.0 & 22982.39 & 20859.02 & 21907.5 & 16862.99 & 8329.92 \\
\hline 2.0 & 41225.69 & 38582.92 & 39282.92 & 33804.63 & 19563.11 \\
\hline 4.0 & 80572.70 & 77717.7 & 78117.7 & 62705.06 & 41502.38 \\
\hline 6.0 & 154918.22 & 151813.3 & 153857.9 & 118620.4 & 79556.49 \\
\hline 8.0 & 292524.49 & 286715.72 & 289051.5 & 239444.4 & 145612 \\
\hline 10.0 & 506006.02 & 499881.64 & 502524.7 & 418796.1 & 294731.1 \\
\hline
\end{tabular}

Similarly to the RBTS the annual Expected EENS, EIC, and EIAR are calculated and shown in Table 8, Also the annual Expected Interruption Costs (EIC) of the base system and the four alternatives for load increment $0 \%, 2 \%$, $4 \%, 6 \%, 8 \%$, and $10 \%$ are shown in Table 9 .

Table 10. The unit capital cost and the annual investment for all alternatives in JEPS

\begin{tabular}{llll}
\hline No. & Alternative Description & Unit Capital Cost & Annual Investment \\
\hline A1 & Add line 132 KV $(70 \mathrm{Km}) @$ Bus 17-19 & $135 \mathrm{~K} \$ / \mathrm{Km}$ & $1002.40 \mathrm{~K} \$ / \mathrm{yr}$ \\
A2 & Add line 400 KV (360 Km ) @ Bus 1-4 & $400 \mathrm{~K} \$ \mathrm{Km}$ & Rejected \\
A3 & Add GT gen. (20 MW ) @ Bus 20 & $17 \mathrm{M} \$$ & $1803.33 \mathrm{~K} \$ / \mathrm{yr}$ \\
A4 & Add ST gen (120 MW) @ Bus 4 & $120 \mathrm{M} \$$ & $12730.00 \mathrm{~K} \$ / \mathrm{yr}$ \\
\hline
\end{tabular}

Table 11. Alternative Annual net gain at different load level

\begin{tabular}{llllll}
\hline \multirow{2}{*}{$\begin{array}{l}\text { Increment } \% \\
\text { Ince System }\end{array}$} & & \multicolumn{4}{l}{ Alternative Annual net gain $(\mathrm{K} \$ / \mathrm{yr})$} \\
\cline { 3 - 6 } & & $\mathrm{A} 1$ & $\mathrm{~A} 2$ & $\mathrm{~A} 3$ & $\mathrm{~A} 4$ \\
\hline 0.0 & 22982.39 & 1120.97 & -14203.51 & 4316.07 & 1922.47 \\
2.0 & 41225.69 & 1640.37 & -13335.63 & 5617.73 & 8932.58 \\
4.0 & 80572.70 & 1852.59 & -12823.41 & 16064.30 & 26340.31 \\
6.0 & 154918.22 & 2102.52 & -14218.12 & 34494.45 & 62631.73 \\
8.0 & 292524.49 & 3613.04 & -12998.77 & 50083.47 & 132989.21 \\
10.0 & 506006.02 & 5121.98 & -11797.12 & 85406.55 & 198544.89 \\
\hline
\end{tabular}

Further analysis can be conducted to evaluate the total cost, which is the sum of annual expected interruption cost and the annual investment for the alternatives. The unit capital cost and the annual investment for all alternatives can be shown in Table 10. At the present load level $(0.0 \%$ increment), Alternative 1 can reduce the expected interruption cost by $2123.37 \mathrm{~K} \$ / \mathrm{yr}$ (22982.39-20859.02). This reduction in much larger than its annual investment of $1002.40 \mathrm{~K} \$ / \mathrm{yr}$ and therefore Alternative 1 is a beneficial option even the present load level. Table 11 shows the alternatives annual net gain at different load levels. This indicates that the addition of the $120 \mathrm{MW}$ units is the best option even when the load has $10.0 \%$ growth

\subsection{Application of Reliability worth Assessment in JEPS Operation}

The JEPS is used to evaluate the reliability indices in a hybrid market. It is assumed that the JEPS become restructured and the followed market pricing criteria is bidding into the pool which is managed by an independent system operator (ISO).

In Jordan Samra Electric Power Generation Company (SEPGCO) was established in 2002 as a new Generation company in order to subject it under privatization process. In 2007, 60\% of Central Electricity Generation Company (CEGCO) was privatized. The first Independent Power Producer (IPP) was established in 2007 as Amman East Station (AES). A second IPP power station was established by the end of 2010. 
Table 12. The profit of each main generating unit in CEGCO

\begin{tabular}{llllll}
\hline & HTPS99 G1 & HTPS264 G2 & REHAB200 G3 & REHAB50 G4 & ATPS650 G5 \\
\hline Profit $(\$ / M W h)$ & -09.31 & -04.61 & 33.92 & 55.54 & 45.19 \\
\hline
\end{tabular}

Table 13. The optimal output with the maximum profit

\begin{tabular}{lllllll}
\hline Load (MW) & $\begin{array}{l}\text { HTPS99 } \\
(\mathrm{MW})\end{array}$ & $\begin{array}{l}\text { HTPS264 } \\
(\mathrm{MW})\end{array}$ & $\begin{array}{l}\text { REHAP200 } \\
(\mathrm{MW})\end{array}$ & $\begin{array}{l}\text { REHAP50 } \\
(\mathrm{MW})\end{array}$ & $\begin{array}{l}\text { ATPS650 } \\
(\mathrm{MW})\end{array}$ & Profit (k\$/h) \\
\hline 800 & 0 & 0 & 100 & 50 & 650 & 35.5425 \\
\hline
\end{tabular}

Table 14. Reliability indices for the 2204th hour in the hybrid market

\begin{tabular}{lllllllll}
\hline $\begin{array}{l}\text { Deman } \\
\mathrm{d}\end{array}$ & $\begin{array}{l}\text { Demand } \\
+ \text { Reserv } \\
\mathrm{e}\end{array}$ & $\begin{array}{l}\text { Units } \\
\text { (CEGCO) }\end{array}$ & committed & $\begin{array}{l}\text { Units } \\
\text { committe } \\
\mathrm{d} \\
\text { (SEGCO) }\end{array}$ & $\begin{array}{l}\text { Units } \\
\text { committe } \\
\mathrm{d}(\text { AES })\end{array}$ & $\begin{array}{l}\text { Committe } \\
\text { d Capacity } \\
(\mathrm{MW})\end{array}$ & $\begin{array}{l}\text { LOLE } \\
(\mathrm{h} / \mathrm{h})\end{array}$ & $\begin{array}{l}\text { EENS } \\
(\mathrm{MWh} / \mathrm{h} \\
)\end{array}$ \\
\hline 2050 & 2255 & $\begin{array}{l}1,2,11-16,19,31-35,37-4 \\
0\end{array}$ & $24,25,26$ & 28,29 & 2240 & 0.000 & 2.53 \\
& & & & & & 3 & \\
\hline
\end{tabular}

CEGCO produces electricity (in MWh) from four main power plants in Jordan; ATPS, HTPS, REHAB, and Risha.SEGCO have a 300 MW combined cycle plant (two GT's and one ST) and two GT's with $100 \mathrm{mw}$ for each. While the AES have only two GT's, $120 \mathrm{MW}$ for each. CEGCO has a long term bilateral contract to run Risha generating units as could as possible as the high priority to run because these units consume a national natural gas. The maximum capacity for this power plant reaches $150 \mathrm{MW}$. CEGCO has another bilateral contract with a customer to supply a demand of $800 \mathrm{MW}$, the average tariff of the energy sold is $70.54 \$ / \mathrm{MWh}$. This profit of each generating unit is detailed as in Table 12. A MATLAB program file, using Revised Simplex Method, has been used to find the optimal units operations to reach the maximum profit for CEGCO to supply a demand of $800 \mathrm{MW}$ with a profit $35.5425 \mathrm{k} \$ \mathrm{~h} \mathrm{~s}$ shown in Table.13. It is noticed that HTPS did not participate to the contract because HTPS generating units can't compete against the other company due to high running cost. CEGCO prefer to run it to reserve generators. Reliability indices for the 2204th hour (the daily peak in the 1st of April) are shown in Table 14. It assumed that all the generators bid at their marginal costs for this hour.

\section{Conclusion}

The different line addition location has completely different impacts on composite system reliability. The different choice of the generating companies to participate in the market for the same committed capacity and demand affect the reliability indices. A Matlab program file, using Revised Simplex Method, is used to find the optimal solution, by determining unit commitment for each generating unit, to reach the maximum profit (or minimize cost) subjected to operational constraints. The needs for power system planners to develop operational strategies by complementing short-term planning with long-term planning based on the cost benefit approach.

\section{References}

Bresesti, P., Calisti, R., Cazzo, M. V., Gatti, A., Provenzano, D., Vaiani, A., \& Vailati, R. (2008). The benefits of transmission expansions in the competitive electricity markets. International Journal of Energy, 34, 274-280. http://dx.doi.org/10.1016/j.energy. 09.008

Buygi, M. O., Shanechi, H. M., Balzer, G., \& Shahidehpour, M. (2003). Transmission Planning Approaches in Restructured Power Systems. 2003 IEEE Power Tech Conference Proceedings, vol. 2, June, Bologna, Italy. Digital Object Identifier: 10.1109/PTC.2003.1304666

De la Torre, S., Conejo, A. J., \& Contreras, J. (2007). Transmission Expansion Planning in Electricity Markets. IEEE Transactions on Power Systems, 23(1), 238-248. http://dx.doi.org/10.1109/TPWRS.913717

Eliassi, M., Seifi, H., \& Haghifam, M. R. (2009). Multi-Objective Value-Based Reliability Transmission Planning Using Expected Interruption Cost Due to Transmission Constraint. Electric Power and Energy Conversion Systems $\sim$ EPECS, 9, 1-8.

Fonseka, P. A. J., \& Shrestha, G. B. (2009). Economic Transmission Planning Model Suitable for a Regulated Network Service Provider, 64 / JOURNAL OF ENERGY ENGINEERING (C) ASCE / SEPTEMBER 2009. http://dx.doi.org/10.1061/_ASCE_0733-9402-135:3-64 
Fu, R., Wei, P., Sun, Y., \& Tang, G. (2008). A new congestion monitoring index constrained multistage transmission expansion planning under market environment (pp. 978-983). 3rd International Conference on Electric Utility Deregulation and Restructuring and Power Technologies DRPT, Nanjing. http://dx.doi.org/10.1109/DRPT.2008.4523548

Mohammad, T. A., \& Mojtaba, S. (2011). A Multi-Objective Framework for Transmission Expansion Planning in Electricity Market. International Review of Electrical Engineering (I.R.E.E.), 6(4).

National Electrical Power Company (NEPCO). Electricity in Jordan, Development of Electricity. Retrieved from http://www.nepco.com.jo/english_improve.html

Samaan, N. (2004). Reliability Assessment of Electric Power Systems using Genetic Algorithms. Texas A\&M University. Retrieved from http://hdl.handle.net/1969.1/1054

Shahidephour, M., \& Yamin, H. (2002). Market Operations in Electric Power System Forecasting, Scheduling, and Risk Management. New York: John Wiley \& Sons. http://dx.doi.org/10.1002/047122412X.ch1

Shayeghi, H., Jalilzadeh, S., Mahdavi, M., \& Hadadian, H. (2008). Studying the influence of two effective parameters on network losses in transmission expansion planning using DCGA. International Journal of Energy Conversion and Management, 49, 3017-3024. http://dx.doi.org/10.1016/j.uncommon. 06.013

Shrestha, G. B., \& Fonseka, P. A. J. (2004). Congestion-Driven Transmission Expansion in Competitive Power Markets. IEEE Transactions on Power Systems, 19(3), 1658-1665.

Sirjani, R., Khaki, B., Neghab, A. P., Mehrtash, A., \& Parastar, A. (2008). A new method for increasing competition in transmission expansion planning (pp.717-721). 2008 IEEE International Conference on Sustainable Energy Technologies ICSET 2008 , November, Singapore.

Wang, P., \& Billinton, R. (2003). IEE Proc.-Gener. Transm. Distrib., 150(5). http://dx.doi.org/10.1049/ip-gtd: 20030723

Wangdee, W. (2005). Bulk Electric System Reliability Simulation and Application. Ph.D. dissertation, Dept. Elec. Eng., University of Saskatchewan, December. Retrieved from http://library2.usask.ca/theses/available/etd-12152005-133551/unrestricted/WijamangdeePhDthesis.pdf

Weron, R. (2006). Modelling and Forecasting Electricity Loads and Prices: a statistical approach. John Wiley \& Sons Ltd. HD9685.A2W47 2007 333.793213015195—dc22.

Wu, F. F., Zheng, F. L., \& Wen, F. S. (2006). Transmission investment and expansion planning in a restructured electricity market. International Journal of Energy, 31, 954-966. http://dx.doi.org/10.1016/j.energy.2005.03.001

\section{Appendix A}

\section{Reliability Indices}

Three different classes of reliability indices can be computed: (a) probability, (b) frequency and (c) duration indices.

a. Probability index:

The state probability $\mathrm{SP}_{\mathrm{j}}$ for each chromosome $\mathrm{j}$ is calculated as follows:

$$
\mathrm{SP}_{\mathrm{j}}=\prod_{\mathrm{i}=1}^{\mathrm{ng}} \mathrm{Gi} . \prod_{\mathrm{i}=1}^{\mathrm{nt}} \mathrm{Ti}
$$

Where $G_{i}=1-F O R_{i}$ if its generator's state $=1$ (up state) or $G_{i}=F O R_{i}$ if its generator's state $=0$ (down state), and $\mathrm{T}_{\mathrm{i}}=1-\mathrm{PT}_{\mathrm{i}} \quad$ if its transmission line's state $=1$ or $\mathrm{T}_{\mathrm{i}}=\mathrm{PT}_{\mathrm{i}} \quad$ if its transmission line's state $=0$.

A threshold probability value is set depending on the required accuracy. If the state probability calculated for a state is less than the threshold value this state is ignored.

The Expected Power Not Supplied (EPNS) for the new state is calculated and the result is saved in the state array.

$$
\mathrm{EPNS}_{\mathrm{j}}=\mathrm{LC}_{\mathrm{j}} \cdot \mathrm{SP}_{\mathrm{j}}
$$

Where $\mathrm{LC}_{\mathrm{j}}$ is the amount of load curtailment for the whole system calculated by the optimal power flow.

b. Frequency Indices: 
The failure frequency for the $\mathrm{j}$ state is calculated using the conditional probability:

$$
\mathrm{FS}_{\mathrm{j}}=\mathrm{SP}_{\mathrm{j}} \cdot \sum_{\mathrm{i}=1}^{\mathrm{ng}+\mathrm{nt}}\left[\left(1-\mathrm{b}_{\mathrm{i}}\right) \cdot \mu_{\mathrm{i}}-\mathrm{b}_{\mathrm{i}} \cdot \lambda_{\mathrm{i}}\right]
$$

Where $\mathrm{FS}_{\mathrm{j}}$ is the failure frequency for state $\mathrm{j}$, and $b_{i}$ is the binary value of component's state number (i) representing a generator unit or transmission line.

c. Duration index:

The failure duration for the $\mathrm{j}$ state is calculated using the following equation:

Where $T_{s j}$ is the failure duration for state $\mathrm{j}$.

$$
T_{s j}=\frac{S P_{j}}{F S_{j}}
$$

\section{Appendix B}

\section{Assessment of Composite System Adequacy Indices}

Annualized adequacy indices for the whole system and for each load bus are calculated using the data saved in the state array. These indices are, Loss of Load Probability (LOLP), Loss of Load Expectation (LOLE), Expected Power Not Supplied (EPNS), Expected Energy Not Supplied (EENS), Loss of Load Frequency (LOLF), and Loss of Load Duration (LOLD). These indices are calculated considering only saved failure states and ignoring success ones.

Let the total number of saved failure states to be (nf), Then the adequacy indices for the whole system are calculated as follows:

$$
\operatorname{LOLP}=\sum_{j=1}^{\mathrm{nf}} \mathrm{SP}_{\mathrm{j}}, \mathrm{LOLF}=\sum_{\mathrm{j}=1}^{\mathrm{nf}} \mathrm{FS}_{\mathrm{J}}, \mathrm{EPNS}=\sum_{\mathrm{j}=1}^{\mathrm{nf}} \mathrm{EPNS}_{\mathrm{J}}, \text { LOLE }=\text { LOLP. } 8760, \text { LOLD }=\frac{\mathrm{LOLE}}{\mathrm{LOLF}}, \text { EENS }=\text { EPNS. } 8760
$$

The same set of indices can be calculated for each load bus considering only failure states resulting in load curtailment at this bus and ignoring all other states.

\section{Appendix C}

\section{The Jordanian Electrical Power System (JEPS)}

The transmission network of the JEPS consists of 46 bus locations connected by 92 lines and transformers, as in the figure below. The transmission lines are at two voltages, $400 \mathrm{KV}$ and $132 \mathrm{KV}$. The JEPS has 40 generating units rating from $10 \mathrm{MW}$ to $200 \mathrm{MW}$. The basic annual peak load for the test system is $2230 \mathrm{MW}$ and the total installed generating capacity is $2525 \mathrm{MW}$. 


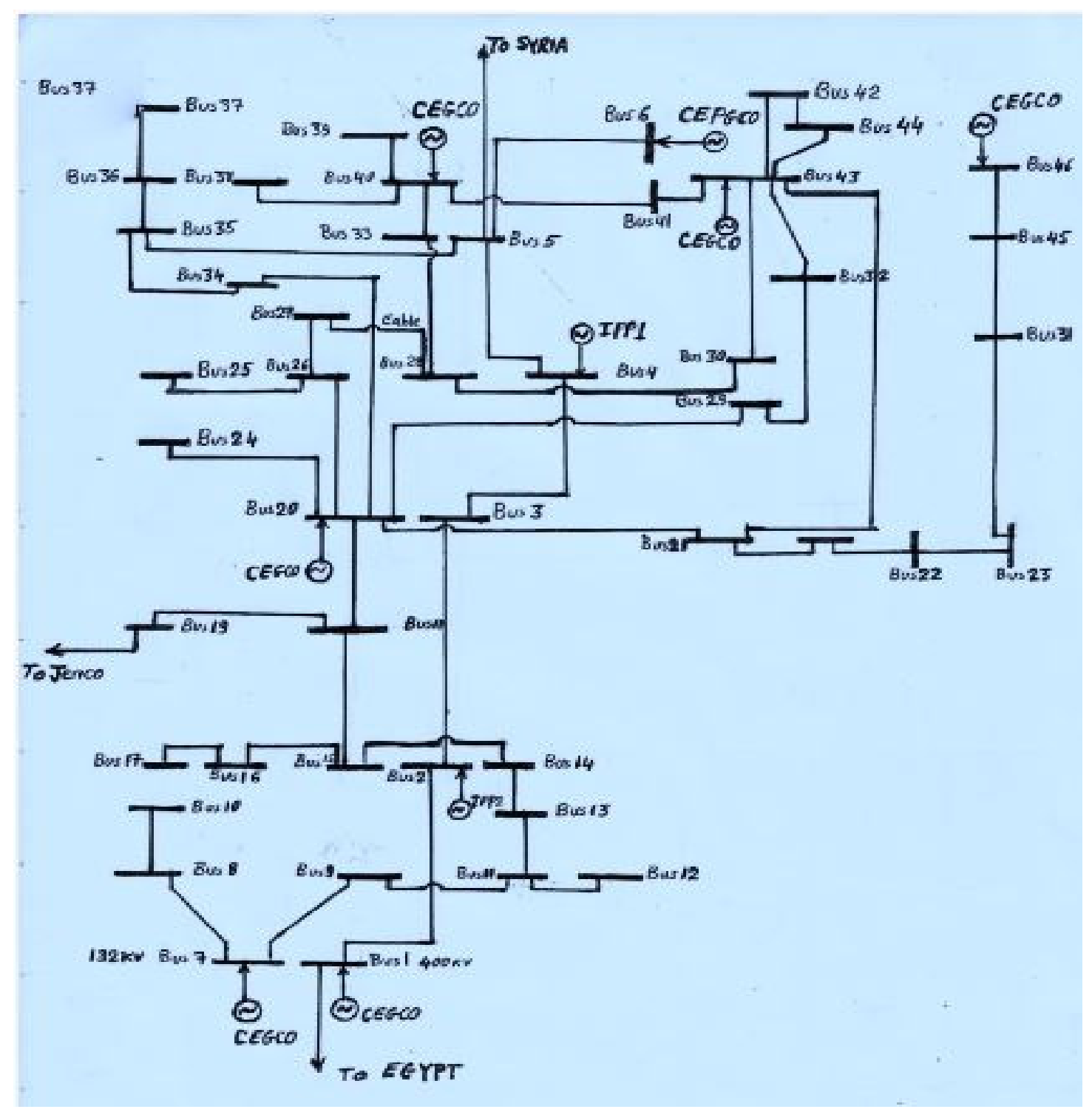

\section{Copyrights}

Copyright for this article is retained by the author(s), with first publication rights granted to the journal.

This is an open-access article distributed under the terms and conditions of the Creative Commons Attribution license (http://creativecommons.org/licenses/by/3.0/). 